\title{
Simulation of the combined effects of artisanal and recreational fisheries on a Mediterranean MPA ecosystem using a trophic model
}

\author{
Camille Albouy $^{1, *}$, David Mouillot ${ }^{1}$, Delphine Rocklin ${ }^{1,2}$, Jean M. Culioli ${ }^{3}$, \\ François Le Loc' $\mathbf{h}^{4}$ \\ ${ }^{1}$ Université Montpellier 2 CC 093, UMR 5119 CNRS-UM2-IFREMER-IRD ECOLAG, 34095 Montpellier, France \\ ${ }^{2}$ Laboratoire de Biologie Halieutique - Département Sciences et Technologies Halieutiques, IFREMER Brest, BP 70, \\ Technopôle Brest Iroise, 29280 Plouzané, France \\ ${ }^{3}$ Office de l'Environnement de la Corse, Reserve Naturelle des Bouches de Bonifacio, 20250 Corte, France \\ ${ }^{4}$ IRD, UMR 212 EME, CRHMT, avenue Jean Monnet 34203 Sète cedex, BP 171, France
}

\begin{abstract}
Marine protected areas (MPAs) have the potential to enhance the long-term sustainability of coastal resources, and the artisanal fisheries which depend on them. However, recreational fisheries, which are increasing their impacts on coastal resources worldwide, may reduce the benefits that MPAs provide to declining artisanal fisheries. Here we used the Bonifacio Straits Natural Reserve (BSNR) Corsica as a study case to simulate the combined effects on coastal resources of artisanal and recreational fishing efforts. The BSNR ecosystem was modelled using mass-balance modelling of trophic interactions. This model was compared to another built on a non-protected area from the same region. We aggregated fishing fleets into artisanal and recreational categories, and we simulated various combinations of fishing effort over a $20 \mathrm{yr}$ dynamic simulation using Ecosim. We showed that fishing activities have an additional top-down effect on the food web and that they decrease the targeted group's biomass, such as piscivorous species. We found, for some trophic groups, non-trivial patterns of biomass variation through trophic cascades. Our trophic approach revealed that some groups may suffer a biomass decrease when MPAs are set or enforced, due to the combined effect of artisanal and recreational fisheries. Overall, our results illustrate the value of modelling to manage MPAs, as a complementary tool to surveys. Models provide the opportunity to anticipate the potential consequences, at the ecosystem level, of socio-political decisions that aim to sustain coastal resources while managing artisanal and recreational fisheries.
\end{abstract}

KEY WORDS: Ecopath with Ecosim $\cdot$ Epinephelus marginatus $\cdot$ MPA $\cdot$ Trophic cascades $\cdot$ Artisanal fisheries $\cdot$ Recreational activities $\cdot$ Mediterranean Sea

Resale or republication not permitted without written consent of the publisher

\section{INTRODUCTION}

Human activities are causing unprecedented changes to coastal marine systems, partly through direct and indirect fishing effects (Jackson et al. 2001). Exploitation can cause major changes in biological assemblages and, ultimately, biodiversity loss that may disrupt the way the ecosystem functions and alter the sustainability of the goods and services provided by marine ecosystems (Lotze et al. 2006, Worm et al. 2006).
There is an urgent need, therefore, to evaluate the potential impact that the different types of fishing activities, alone and in combination, can have on the sustainability of coastal resources and on the general function of coastal ecosystems. The western Mediterranean Sea is one of the most overpopulated coastal areas in Europe, and the increasing size of the human population may bring an increase in recreational fishing activities. This has been recognized as one of the most common leisure activities in coastal zones, involv- 
ing several methods (boat-fishing, spearfishing, shore fishing). Moreover, it has been observed that the ever increasing recreational fishing effort (Cooke \& Cowx 2004, Lloret et al. 2008a) may locally surpass that of artisanal fisheries (Morales-Nin et al. 2005), although discards are usually less important in recreational fisheries. Commercial and recreational activities have similar demographic and ecological effects on fish populations and may provoke serious ecological and economic damage (e.g. Coleman et al. 2004). For instance, spearfishing can affect benthic communities inhabiting shallow rocky bottoms (Dulvy \& Polunin 2004, Meyer 2007). Over the last $20 \mathrm{yr}$, catches of several commercial stocks have been in decline in the western Mediterranean Sea while, in parallel, the recreational fishing effort has increased (Morales-Nin et al. 2005). Several policies have been applied to protect coastal ecosystems, biodiversity and artisanal fisheries, in response to the symptoms of overexploitation. To reduce such negative impacts, marine protected areas (MPAs) have been implemented worldwide as part of an ecosystem-based approach to coastal management (e.g. Lubchenco et al. 2003). However, the term MPA encompasses a large range of protection levels, from partially protected to entirely no-take areas. These restriction levels are often a result of a compromise between conservationists and extractive user groups (professional and recreational). However, positive reserve effects such as the spillover of biomass to professional fisheries (Forcada et al. 2009) have not reversed a decline in some Mediterranean artisanal fisheries (Gómez et al. 2006). Thus, the sustainability of artisanal fisheries on Mediterranean coasts is becoming ever more challenging, and there is increasing pressure from recreational fisheries which may further weaken such traditional socio-economic activities.

The study of interactions between species, and not just a mono-specific approach to a fish stock, is necessary to understand the whole dynamics of assemblages targeted by fishing activities, and the consequences for ecosystems (Gascuel 2005). Therefore, a consensus has emerged in fishery science to complement the 'single species' approach with an ecosystem approach to fisheries (Walters et al. 1997, Cury et al. 2005, 2008). This modern approach explicitly considers direct and indirect ecological interactions, particularly trophic links between ecosystem components, and allows simulations of the impacts of different fishing activities at the level of whole species assemblages. MPAs offer unique opportunities to study the behavior of species assemblages that are either facing disturbances or benefitting from restrictive policies. In addition, they have the advantage of being carefully monitored, and data sets are usually available over several years (e.g. Claudet et al. 2006, Guidetti et al. 2008).
The Bonifacio Straits Natural Reserve (BSNR), a multiple-use Mediterranean MPA, provides an opportunity to study the combined effects of artisanal and recreational fisheries on a Mediterranean ecosystem, within a multi-specific context. We built an Ecopath model with Ecosim (EwE) for this particular ecosystem. The BSNR is characterized by a predominantly rocky substrate, an ecosystem which is generally considered as one of the most impacted by human activities (Halpern et al. 2008). Moreover, the BSNR has a high touristic value, and attracts a large number of recreational anglers, particularly in the summer. This pressure, combined with the local small-scale artisanal fishery, may cause intense fishing effort on the unprotected parts of this ecosystem (Mouillot et al. 2008). Given the declining artisanal fisheries in the Mediterranean (Gomez et al. 2006), it is crucial to study interactions between commercial and recreational fishing in order to promote conservation measures that are (1) beneficial to the artisanal activity and (2) able to sustain the function of coastal ecosystems.

MPA managers are searching for tools to help them understand how ecosystems function and to evaluate policy effects. They need to assess the effects of their decisions in order to formulate new measures for protection. The evaluation of reserve effects usually relies on empirical results showing the gradients of species biomasses or catches (e.g. Russ \& Alcala 1996, Stobart et al. 2009). Such observations, although necessary, do not allow predictions for different scenarios and cannot provide insight into the mechanisms which cause the observed patterns. To overcome these limitations, there is an urgent need to develop the modelling of MPA functions (e.g. Gardmark et al. 2006, Pérez Ruzafa et al. 2008).

EwE tools allow users to model exploited ecosystems. They integrate several levels of analysis: Ecopath is a snapshot of annual trophic flows within an ecosystem, while Ecosim is able to simulate temporal trends of food web properties under different scenarios of fishing pressure (Christensen \& Walters 2004).

Here, using such trophic modelling tools, we studied the combined effects of artisanal and recreational fisheries on BSNR resources. To achieve this, we simulated scenarios with various combinations of commercial versus recreational fishing pressures.

\section{MATERIALS AND METHODS}

Study site and fishery fleets. The BSNR is located in southern Corsica (France; Mediterranean Sea, Fig. 1). Its surface area is approximately $800 \mathrm{~km}^{2}$ and the maximum depth is $158 \mathrm{~m}$. The BSNR is characterized by a predominantly rocky substrate and Posidonia 


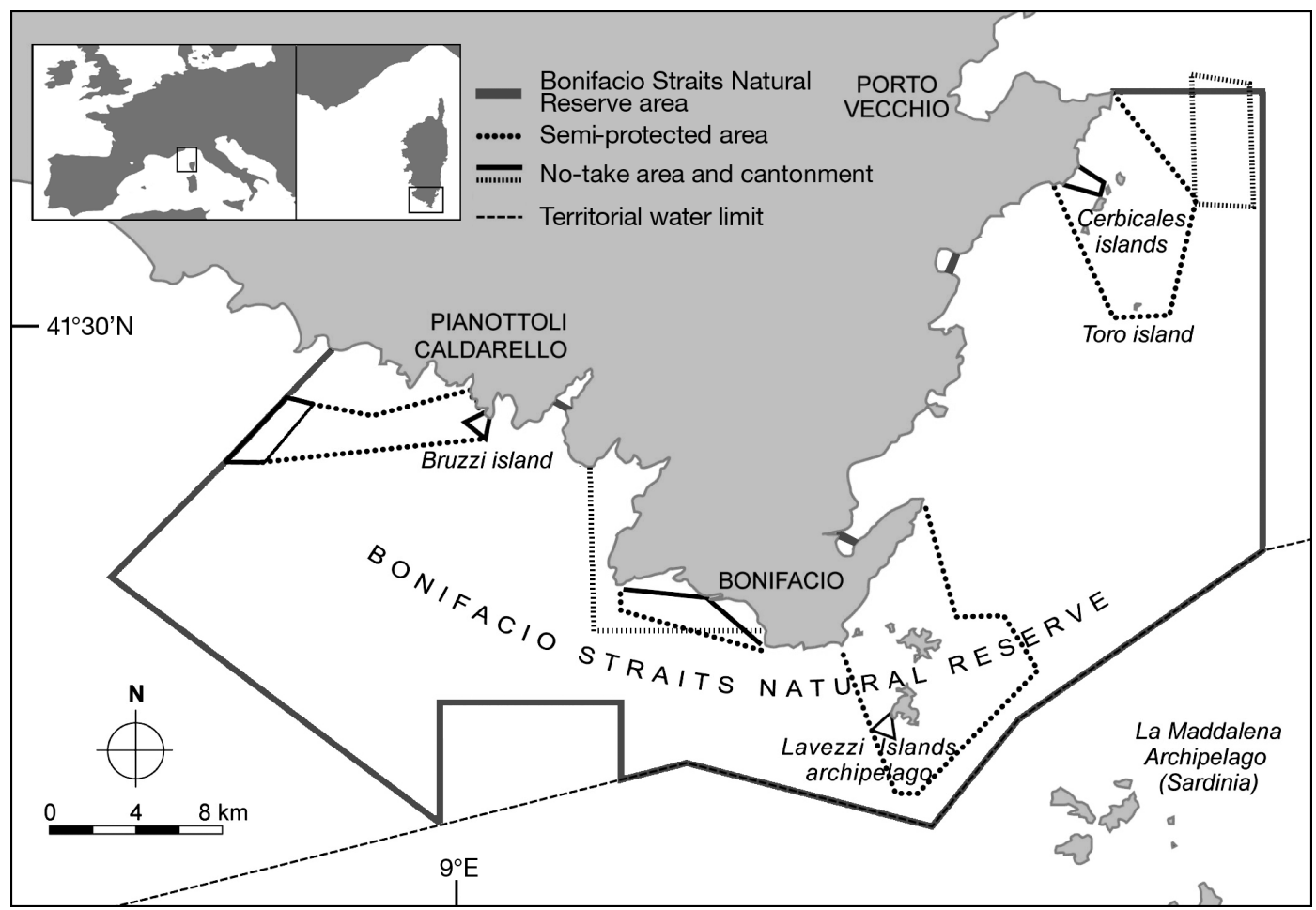

Fig. 1. Bonifacio Strait Natural Reserve (BNSR) study area. In semi-protected areas spearfishing is prohibited. The perimeter of the reserve is also the limit of the Ecosim (EwE) model

oceanica seagrass beds at shallow depths (Pluquet 2006). It was created in September 1999 and encompasses the Lavezzi Islands Reserve (LIR) created in 1982 (Mouillot et al. 2002). The LIR has been partially protected from spearfishing and other recreational fishing activities whereas traditional fisheries, using trammel nets, are permitted. In 1999, protection was strengthened (1) at the local level with the prohibition of longlines for recreational activities and with an additional $0.9 \mathrm{~km}^{2}$ no-take area for a total of $50.5 \mathrm{~km}^{2}$ in the LIR, and (2) at the regional level with the creation of the BSNR (Fig. 1); 5 no-take areas and 2 'cantonments' (voluntary no-fishing zones) $\left(12 \mathrm{~km}^{2}\right.$ ), where all fishing activities and scuba-diving are forbidden, were created. Moreover, the limitation of recreational fishing activities was extended through partially protected areas $\left(120 \mathrm{~km}^{2}\right)$, where spearfishing is forbidden while professional fishing is allowed (Mouillot et al. 2002). The aim of this MPA is to ensure protection of the ecological heritage while taking various economic factors into account, including the sustainability of the local small-scale artisanal fishery.

The BSNR artisanal fleet is composed of small boats (average length $7.7 \mathrm{~m}$ ) fishing on the continental shelf (Mouillot et al. 2008). Generally, trammel nets are set for $24 \mathrm{~h}$ at depths ranging from 20 to $60 \mathrm{~m}$. The minimum mesh size used for fish is $62.5 \mathrm{~mm}$.
Ecopath and Ecosim models. Ecopath: Ecopath and Ecosim (version 6.0.7.114) models (Pauly et al. 2000, Christensen \& Walters 2004) were employed to ensure energy balance and to quantify trophic flows in aquatic ecosystems. Basically, implementation of Ecopath is based on 2 master equations, one describing the production term and the other the energy balance for each group.

The first equation (Eq. 1) describes how the production term for each group $i$ can be split into several components of the system.

$$
P_{i}=\sum_{j=1} B_{j} \times M 2_{i j}+P_{i} \times\left(1-E E_{i}\right)+Y_{i}+E_{i}+B A_{i}
$$

The production $(P)$ of each group $(i)$ is divided into predation mortality $\left(M 2_{i j}\right)$ caused by the biomass of predators $\left(B_{j}\right)$, exports from the system both from fishing activity $\left(Y_{i}\right)$ and other emigration $\left(E_{i}\right)$, the biomass accumulation rate $\left(B A_{i}\right)$, and other mortality $\left(1-E E_{i}\right)$. The other mortality term includes natural mortality due to diseases, old age, starvation, etc. This term is constructed using an ecotrophic efficiency term $\left(E E_{i}\right)$, which represents the proportion of production $\left(P_{i}\right)$ that is exported out of the ecosystem or consumed by predators within it.

The second equation (Eq. 2) expresses the principle of conservation within a group: Consumption = Production + Respiration + Unassimilated food. 


$$
Q_{i}=P_{i}+R_{i}+U_{i}
$$

Eqs. (1) \& (2) can be re-expressed as:

$$
\begin{aligned}
(P / B)_{i} \times B_{i}= & \sum_{j=1}\left(B_{j} \times(Q / B)_{j} \times D C_{j i}\right)+ \\
& (P / B)_{i} \times B_{i} \times\left(1-E E_{i}\right)+Y_{i}+E_{i}+B A_{i}
\end{aligned}
$$

and

$$
(Q / B)_{i} \times B_{i}=B_{i} \times(P / B)_{i}+R_{i}+U_{i}
$$

where $(P / B)_{i}$ represents the production of group (i) per unit of biomass; $(Q / B)_{i}$ is the consumption rate of group (i) per unit of biomass, $D C_{j i}$ is the diet composition that indicates the proportion of (i) that is in the diet of predator $(j), R_{i}$ is for respiration and $U$ represents the unassimilated food rate of group (i).

For parameterization, EwE sets up a system with as many linear equations as there are groups in a system where, for each equation, 3 of the basic parameters, i.e. $B_{i},(P / B)_{i r}(Q / B)_{i}$, and $E E_{i}$, have to be known for each group (i). If, and only if, all 4 of these parameters are entered, the program will prompt you during basic parameterization. If only 3 of the basic parameters are entered, other parameters such as the following must be implemented: catch rates, net migration rates, biomass accumulation rates, assimilation rates and diet compositions.

Ecosim: Ecosim provides a dynamic simulation capability at the ecosystem level, with key initial parameters inherited from the Ecopath model (Christensen \& Walters 2004). Ecosim uses a system of differential equations that derive from the Ecopath master equation (Eq. 3). The set of equations is solved in Ecosim using an Adams-Bashford or a Runge-Kutta 4th order integration routine (Christensen et al. 2005).

$$
\frac{\mathrm{d} B_{i}}{\mathrm{~d} t}=(P / Q)_{i} \times \sum_{j=1} Q_{j i}-\sum_{j=1} Q_{i j}+I_{i}-\left(M_{i}+F_{i}+e_{i}\right) \times B_{i}
$$

where $\mathrm{d} B_{i} / \mathrm{d} t$ is the biomass growth rate of group (i) during the time interval $\mathrm{d} t,(P / Q)_{i}$ is the net growth efficiency, $M_{i}$ the non-predation natural mortality rate, $F_{i}$ is the fishing mortality rate, $e_{i}$ the emigration rate, $I_{i}$ the immigration rate, and $I_{i}-e_{i} B_{i}$ the net migration rate. Calculations of the consumption rate $\left(Q_{j i}\right)$ are based upon the 'foraging arena' theory, where the biomass of $i$ is divided between available prey (vulnerable, $V_{i}$ ) and unavailable prey (non-vulnerable fraction, $B_{i}-V_{i}$ ).

Ecopath model parameters. The system modelled in this study represented an annual average of trophic flows on the whole BSNR area in 2000 to 2001. The model included 32 biological groups depicting the main trophic components of the studied ecosystem. It includes 12 fish groups (targeted and non-targeted fish; Table 1). Groups can correspond to single species or trophic aggregation, based on diet in our case. All details describing the parameter estimations and species grouping are presented in Supplement $1 \mathrm{~A}$ at www.int-res.com/articles/suppl/m412p207_supp.pdf.

Fish groups based on diet composition: In order to create homogeneous fish groups according to their trophic role in the ecosystem, a preliminary diet matrix was gathered from published gut content items (54 species present in the BSNR). The diet matrix (Supplement 1B) was constructed preferentially using data from local studies (Supplement 1C), and from the Mediterranean Sea when necessary. We then calculated a Bray-Curtis distance matrix between species pairs. A $k$-means partitioning method was performed to determine the optimal composition of each group (Legendre \& Legendre 1998). The optimal number of fish groups was selected using the highest SSI (simple tructure ndex) according to Dolnicar et al. (1999). Since the groups were based on diet, the aggregation should not hinder our ability to detect trophic cascades. Some species of particular ecological interest were excluded from fish trophic groups to constitute their own group: among these were the dusky grouper Epinephelus marginatus, a protected top-predator, the European barracuda Sphyraena sphyraena, the small-spotted catshark Scyliorhinus canicula and the salema Sarpa salpa, which is the only herbivorous fish in the BSNR.

Biomasses and catches: Biomass estimations of fish groups were based on a visual count method, using a circular fixed point (Bohnsack \& Bannerot 1986, Samoilys \& Carlos 2000). The underwater visual census (UVC) method is commonly employed for fish counts in Mediterranean marine environments (Guidetti et al. 2003, Claudet et al. 2006, Harmelin-Vivien et al. 2008).

UVCs were carried out monthly by scuba-diving from 2000 to 2001 in the BSNR. Observed fish were classified into 3 size classes (based on length), and the abundance of each species per length class was estimated. Length-weight relationships between size class and fish weight were estimated using the literature (Bauchot \& Pras 1980, Froese \& Pauly 2010). For species not observed in UVCs, biomass values were collected from the literature from other Mediterranean trophic models (Pinnegar \& Polunin 2004, Coll et al. 2006). All details are given in Supplement $1 \mathrm{~A}$.

A second data source for estimating biomass of fish groups was based on catches of the BSNR artisanal fishery. Data were collected during the warm season (between April and September) just after the implementation of the MPA. Fish landings were randomly sampled from fishing boats in the BSNR. All caught species were measured and their total weight was also estimated using size-weight class correspondences. Overall, 65 species were sampled including teleosts and elasmobranchs. This pool of species included most species known to live in the BSNR, excluding very 
Table 1. Input and output (values in italics) parameters used to model the Bonifacio Strait Natural Reserve ecosystem groups. $B$ : biomass $\left(\mathrm{t} \mathrm{km}{ }^{-2}\right) ; P / B$ : production/biomass ratio $\left(\mathrm{yr}^{-1}\right) ; Q / B$ : consumption/biomass ratio $\left(\mathrm{yr}^{-1}\right)$; EE: ecotrophic efficiency; $U / Q$ : unassimilated food. Landing and discards are expressed in $\mathrm{t} \mathrm{km}^{-2} \mathrm{yr}^{-1}$; TL: trophic level; art: artisanal fishing; rec: recreational fishing

\begin{tabular}{|c|c|c|c|c|c|c|c|c|c|c|}
\hline \multicolumn{2}{|c|}{ Groups } & \multirow{2}{*}{$\begin{array}{c}B \\
0.007\end{array}$} & \multirow{2}{*}{$\begin{array}{l}P / B \\
0.01\end{array}$} & \multirow{2}{*}{$\begin{array}{c}/ B \\
13.49\end{array}$} & \multirow{2}{*}{$\begin{array}{c}E E \\
0.00\end{array}$} & \multirow{2}{*}{$\begin{array}{c}U / Q \\
0.2\end{array}$} & \multirow{2}{*}{$\begin{array}{c}\text { Landings } \\
\text { art. fleet }\end{array}$} & \multirow{2}{*}{$\begin{array}{c}\text { Landings } \\
\text { rec. fleet }\end{array}$} & \multirow{2}{*}{$\begin{array}{c}\text { Discards } \\
\text { art. fleet }\end{array}$} & \multirow{2}{*}{$\begin{array}{c}\mathrm{TL} \\
5.22\end{array}$} \\
\hline 1 & Tursiops truncatus & & & & & & & & & \\
\hline 2 & Sphyraena sphyraena & 0.253 & 0.60 & 5.00 & 0.02 & 0.2 & 0.0005 & 0.0021 & 0.0001 & 4.96 \\
\hline 3 & Scyliorhinus canicula & 0.06 & 1.32 & 4.06 & 0.01 & 0.2 & 0.0007 & - & - & 4.6 \\
\hline 4 & Piscivorous fish & 3.48 & 0.89 & 3.56 & 0.39 & 0.2 & 0.0194 & 0.0277 & 0.0004 & 4.45 \\
\hline 5 & Small pelagic feeders & 1.15 & 0.93 & 4.47 & 0.93 & 0.2 & 0.0067 & 0.0144 & 0.0001 & 4.52 \\
\hline 6 & Epinephelus marginatus & 0.874 & 0.28 & 2.74 & 0.00 & 0.2 & 0.0006 & - & 0.0003 & 4.30 \\
\hline 7 & Opportunistic piscivorous fish & 7.56 & 0.64 & 4.83 & 0.96 & 0.2 & 0.0248 & 0.0160 & 0.0005 & 4.13 \\
\hline 8 & Cephalopods & 3.42 & 2.12 & 5.27 & 0.97 & 0.4 & 0.0037 & 0.0002 & - & 3.94 \\
\hline 9 & Birds & 0.001 & 5.74 & 85.03 & 0.03 & 0.2 & - & - & - & 4.43 \\
\hline 10 & Benthic invertebrate feeders & 2.84 & 1.06 & 4.05 & 0.93 & 0.2 & 0.0065 & 0.0174 & 0.0004 & 3.65 \\
\hline 11 & Zooplanktivorous fish & 13.30 & 0.44 & 9.42 & 0.95 & 0.2 & 0.0002 & 0.0001 & 0.0001 & 3.39 \\
\hline 12 & Mollusc feeders & 10.08 & 0.75 & 6.60 & 0.90 & 0.2 & 0.0021 & 0.0084 & 0.0001 & 3.31 \\
\hline 13 & Benthic invertebrate feeders 2 & 8.00 & 1.03 & 6.40 & 0.96 & 0.2 & 0.0055 & 0.0035 & 0.0002 & 3.3 \\
\hline 14 & Shrimp & 5.86 & 3.08 & 7.20 & 0.95 & 0.2 & - & - & - & 2.73 \\
\hline 15 & Macrocarnivorous fish & 1.15 & 0.93 & 4.47 & 0.99 & 0.2 & 0.0030 & 0.0087 & 0.0001 & 2.91 \\
\hline 16 & Decapods & 29.28 & 3.11 & 15.39 & 0.99 & 0.2 & - & - & - & 2.96 \\
\hline 17 & Lobster \& spiny lobster & 2.43 & 0.45 & 7.50 & 0.73 & 0.2 & 0.0197 & - & - & 2.83 \\
\hline 18 & Gastropods & 29.32 & 1.94 & 10.89 & 0.95 & 0.2 & - & - & - & 2.45 \\
\hline 19 & Zooplankton & 4.11 & 50.86 & 172.92 & 0.95 & 0.2 & - & - & - & 2.45 \\
\hline 20 & Polychaetes & 49.87 & 3.42 & 19.57 & 0.99 & 0.6 & - & - & - & 2.44 \\
\hline 21 & Suspension feeders & 47.87 & 1.52 & 6.78 & 0.95 & 0.4 & - & - & - & 2.28 \\
\hline 22 & Echinoderms & 11.20 & 0.51 & 2.82 & 0.94 & 0.6 & - & - & - & 2.12 \\
\hline 23 & Protozoan plankton & 44.18 & 90.00 & 305.16 & 0.95 & 0.4 & - & - & - & 2.11 \\
\hline 24 & Sarpa salpa & 0.30 & 0.58 & 9.24 & 0.22 & 0.2 & 0.0004 & - & 0.0002 & 2.07 \\
\hline 25 & Other crustaceans & 10.02 & 20.54 & 94.00 & 0.99 & 0.2 & - & - & - & 2.05 \\
\hline 26 & Amphipods & 22.86 & 9.15 & 22.09 & 0.95 & 0.4 & - & - & - & 2.09 \\
\hline 27 & Bivalves & 12.19 & 2.10 & 8.95 & 0.99 & 0.4 & - & - & - & 2.11 \\
\hline 28 & Macroplankton & 43.41 & 25.43 & 71.20 & 0.95 & 0.4 & - & - & - & 1.68 \\
\hline 29 & Phytoplankton & 4.18 & 114.00 & - & 0.99 & - & - & - & - & 1 \\
\hline 30 & Macro-algae & 150.62 & 13.30 & - & 0.95 & - & - & - & - & 1 \\
\hline 31 & Posidonia oceanica & 357.79 & 14.92 & - & 0.002 & - & - & - & - & 1 \\
\hline 32 & Detritus & 230.85 & - & - & 0.37 & - & - & - & - & 1 \\
\hline
\end{tabular}

small fish species (adult size $<10 \mathrm{~cm}$ ) such as Gobiidae and Blenniidae and very large transient species such as tunas. Discards data were also available from 2004 to 2006 (Rocklin et al. 2009).

The exploited biomass of some fish species (Supplement 1A) was inferred from artisanal fishing effort during the fishing season (2000 to 2001). It was then divided by the fishing mortality rate $(F)$ and compared to other available data estimated for a similar ecosystem (Calvi Bay, Corsica, France; Pinnegar \& Polunin 2004).

Recreational fishing activities were divided into spearfishing, on the one hand, and boat fishing and shore fishing activities, on the other hand. No data on recreational fishing catches were available for the study area. We used a list of species targeted by spearfishing provided by BSNR managers and a ratio from a study carried out in a Mediterranean MPA displaying similar habitats and similar species (Cap Creus, Spain,
Lloret et al. 2008b). This study estimated that the biomass caught by spearfishers was equivalent to $40 \%$ of the total biomass extracted annually by the artisanal fleet. Similarly, following Morales-Nin et al. (2005), we made the assumption that the level of exploitation by boat and shore fishing is common to north-shore Mediterranean countries.

Target fish species were different depending on fishing gears, and this was determined based on information from the literature and expert opinions (Supplement $1 \mathrm{C}$ ). Such differences were taken into account and re-expressed proportionate to the biomass of each species. In order to create one fleet representing all recreational fishing activities, the biomass of each target group was added to different fleets (boat-fishing, spearfishing, shore fishing).

Estimation of fish $Q / B$ and P/B: Consumption/ biomass $(Q / B)$ ratios were then calculated according to 
the empirical regression of Pauly (1989) and Christensen \& Pauly (1993):

$$
\begin{aligned}
& \log Q / B=7.964-0.204 \log W_{\infty}-1.965 T^{\prime} \\
& +0.083 A+0.532 h+0.398 d
\end{aligned}
$$

where $W_{\infty}$ (or asymptotic weight) is the mean weight that a population would reach if it were to grow indefinitely, $T^{\prime}$ is the mean environmental temperature (for the BSNR $18.6^{\circ} \mathrm{C}$ for 2000 to 2001 ; see Supplement 1D for estimation) expressed as $1000 /\left({ }^{\circ} \mathrm{C}+273.15\right), A$ is the aspect ratio of the caudal fin indicative of metabolic activity and expressed as the ratio of the square of the height of the caudal fin and its surface area, $h$ and $d$ are dummy variables indicating herbivores $(h=1, d=$ $0)$, detritivores $(h=0, d=1)$ and carnivores $(h=0, d=$ 0 ). Usually $W_{\infty}$ was calculated from $L_{\infty}$ using published length/weight parameters $a$ and $b$. However, where asymptotic length $\left(L_{\infty}\right)$ was not available, we used estimated maximum lengths for Corsican species based on Miniconi (1994) and we assumed that $L_{\max } / 0.95 \approx L_{\infty}$ (Pauly 1984).

The $P / B$ ratio was given by Beverton \& Holt (1956), demonstrating that total mortality $(Z=P / B)$ of a fish population, from which individuals grow according to the Von Bertalanffy Growth Function (VBGF), can be expressed by:

$$
Z=P / B=\frac{K \times\left(L_{\infty}-L_{\mu}\right)}{L_{\mu}-L^{\prime}}
$$

where $L_{\infty}$ is the asymptotic length, i.e. the mean size that individuals would reach if they could live and grow indefinitely, $K$ is the VBGF curvature parameter (expressing the rate at which $L_{\infty}$ is reached), $L_{\mu}$ the mean length of the population, computed from $L^{\prime}$ upward. Here, $L^{\prime}$ represents the mean length at recruitment to the fishery, assuming knife-edge selection.

Total $Q / B, P / B$, and diets for each fish group were calculated taking the relative biomass of each species in their trophic group into account.

Balancing the Ecopath model. To balance our Ecopath model we did not use the Automatic Mass Balance Procedure proposed by Kavanagh et al. (2004). Instead, an ecological step-by-step approach was employed to find a more realistic equilibrium (Christensen et al. 2005). First, a model with all parameters available was created and basic outputs estimated. Three fish groups (macro-carnivorous fish, small pelagic feeders and benthic invertebrate feeders), a lobster/spiny lobster group and echinoderms presented an ecotrophic efficiency higher than 1, revealing an overpredation on these groups. The model was therefore balanced by reducing the predation on those 5 groups and by reallocating the consumption to other prey groups.

Ecological indicators from Ecopath. To interpret the Ecopath model, the software EwE includes a large number of ecological indicators based on trophic flows, thermodynamic concepts, information theory and network analysis (Christensen \& Walters 2004, Coll et al. 2006). To calculate trophic levels, a value of 1 was assigned to primary producers and detritus. For consumers, a trophic level of 1 plus the weighted average of the prey's trophic level was assigned. Other indicators were provided at the system scale. For instance the ratio of system primary productivity over biomass $(P / B)$ varies with the development status of the system (Christensen \& Pauly 1993). Developing systems tend to have a high $P / B$, due to low biomass and high production values, while developed systems tend to have high biomass and low production rate values. Odum (1971) described the primary production over respiration ratio $\left(P_{\mathrm{p}} / R\right)$ as an important descriptor of ecosystem maturity. For immature systems, it is assumed that $P_{\mathrm{p}}$ exceeds total $R$, whilst for mature systems the ratio would tend to unity $\left(P_{\mathrm{p}} / R=1\right)$. The Finn's cycling index expresses the percentage of total throughput (sum of all flows in a system) that is actually recycled (Finn 1976), and can be related to ecosystem maturity (Christensen \& Pauly 1993). In order to represent transfer efficiencies, i.e. the energy transferred from a trophic level to the next trophic level through consumption, 'Lindeman spine' (Fig. 2) analysis synthesizes the trophic structure of 32 groups into a simple linear food-chain (Odum 1969, Christensen \& Pauly 1993).

The mixed trophic impact routine derived from economic theory (Ulanowicz \& Puccia 1990), shows direct and indirect impacts that a very small increase in the biomass of a group has on other groups of the system. All these indicators were analyzed and compared to other models (Christensen \& Pauly 1993) in order to replace the BSNR trophic model within a wider context.

Building and simulating the Ecosim model. The Ecosim model was built from the BSNR Ecopath model and simulations were then run considering 2 assumptions. Firstly, over recent years (2000 to 2008), the number of active professional fishing boats has remained constant. Secondly, no major environmental disturbance (pollution, etc.) has impacted the ecosystem over that period. Variability in phytoplankton and zooplankton production, due to climatic factors, was modelled by generating a proportional environmental seasonal forcing function (Supplement 1E). Data related to variability in phytoplankton production were extracted from Bosc et al. (2004) for the period 2000 to 2001. For zooplankton, data were extrapolated from phytoplankton (Supplement 1E) to infer monthly values after a lag of 1 mo (Jamet et al. 2005).

One key feature of Ecosim is its ability to explore how the biomasses of different groups were controlled, with the implications for system dynamics. The 2 ex- 


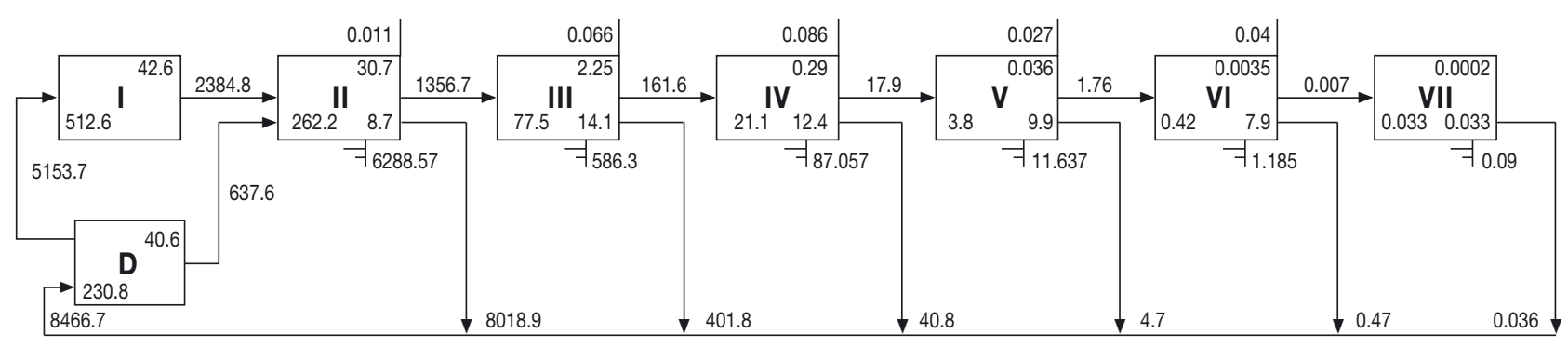

Fig. 2. Bonifacio Strait Natural Reserve (BNSR) ecosystem flow diagram organized by integer trophic levels (TL) in the form of a Lindeman spine. Primary producer (I) and detritus (D) are separated to clarify the representation. TST: total system throughput; Trans Eff: transfer efficiency

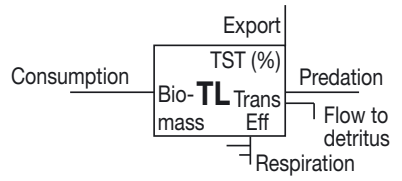

treme views were top-down and bottom-up controls (Christensen et al. 2005). This was modelled using vulnerability $(V)$, expressing the maximum increase in predation mortality under conditions of high predator/prey abundance. Low vulnerability (close to 1) indicates that an increase in predator biomass will not result in any substantial increase in predation mortality, and can be related to bottom-up effects. High vulnerability indicates that if the predator biomass is doubled, it will result in an increase of the predation mortality for a given prey species, and can be related to top-down effects (Christensen et al. 2005).

Default values of vulnerabilities $(V=2)$ were used to represent mixed flow control, while values of $V=1$ were set to describe vulnerability of zooplankton to 2 of its predators (zooplanktivorous fish and polychaetes) to match with a bottom-up flow control (Cury et al. 2000). Impact of mollusc feeders on bivalves and polychaetes was modified to be top-down controlled $(V=10)$, the same for vulnerability of zooplankton and suspension feeders on phytoplankton. Due to lack of data, this Ecosim model was not fit to time series.

In order to study the combined influences of recreational and artisanal fishing activities on the food web and on available resources, simulations of variations in fishing efforts were carried out over $20 \mathrm{yr}$. The initial value of fishing effort was set to 1 for both fishing types (the effort measured in 2000 to 2001) and varied from 0 to 4 by steps of 0.2 (a total of 440 simulations). In other words, we simulated a total prohibition of the artisanal fishery, a total prohibition of recreational activities, a 4 -fold increase of these 2 fishing activities, and all combinations between these extreme possibilities. Even if our study could not rely on a rigorous estimation of recreational catches, which would be challenging to carry out in such a large MPA, the expert knowledge of BSNR managers and the data from comparable studies (Morales-Nin et al. 2005, Lloret et al. 2008a) suggest that recreational activities may extract be- tween 40 and $100 \%$ of the artisanal fishery production. Such values were contained in the range of simulated fishing efforts (0 to $400 \%$ ), which thus embrace realistic scenarios. After each simulation, the biomass ratio of each targeted fish group (end value /start value) was determined and compared to the initial value, and expressed as a percentage of variation.

\section{RESULTS}

\section{Ecopath model}

Based on available literature on fish diets, 8 groups were created using the SSI index and a $k$-means partitioning algorithm. The diet matrix and the composition of fish groups are available in Supplements $1 \mathrm{~B}$ and $1 \mathrm{C}$, respectively, at www.int-res.com/articles/ suppl/m412p207_supp.pdf. Biomasses of fish groups, invertebrate groups and primary producer groups represented $4.4,28.5$ and $46.2 \%$ of the total biomass, respectively. Biomass extracted by fishing activities represented $0.4 \%$ of the total fish and lobster biomasses in the BSNR ecosystem, which is equivalent to a global biomass extraction of $152 \mathrm{t}$ for the whole BSNR annually. The production of artisanal and recreational fishing activities (boat and spearfishing combined together) was estimated at ca. 65 and $87 \mathrm{t} \mathrm{yr}^{-1}$, respectively. By comparison, dolphins consume a biomass of $0.094 \mathrm{t} \mathrm{km}^{-2} \mathrm{yr}^{-1}$ (equivalent to $75 \mathrm{t}$ on the BSNR), which is very close to the biomass exploited by the professional fleet $\left(0.092 \mathrm{t} \mathrm{km}^{-2}\right)$.

Input parameters and basic estimate parameters of the Ecopath model are presented in Table 1. Ecotrophic efficiencies were close to 1 for many groups, while for others, such as the bottlenose dolphin Tursiops truncatus, birds, European barracuda Sphyraena sphyraena, and small-spotted catshark Scyliorhinus canicula, EE was very low $(<0.05)$, indicating that the 
consumption of these groups is minimal. The pedigree index of the model was 0.61 (Table 2), suggesting the relative high quality of the data used.

Results of the BSNR model (Table 1) revealed that groups were organized into 5 trophic levels (TL). The highest TLs corresponded to top predators such as bottlenose dolphin, piscivorous fishes, Sphyraenasphyraena, Scyliorhinus canicula, and birds.

Table 2 comprises summary statistics computed by Ecopath. These statistics allowed comparisons with other ecosystems (protected Mediterranean rocky littoral system versus non-protected) and were useful attributes for assessing ecosystem development and maturity. For instance, the total primary production/ total respiration ratio $\left(P_{\mathrm{p}} / R\right)$ was equal to 1.12 , the total primary production/total biomass $(P / B)$ was equal to 8.91, and the Finn's cycling index was $10.71 \%$.

The 'mixed trophic impact analysis' (MTI, Fig. 3) routine can be seen as a sensitivity analysis and was used to reveal the influence, through trophic cascades, of one group on the others. Here we used this routine to evaluate both direct and indirect impacts of all groups on the system. One of these direct impacts is illustrated by the decrease in the salema Sarpa salpa induced by a small increase in the dusky grouper Epinephelus marginatu, its main predator. An indirect impact is illustrated by the group of small pelagic feeders. A small increase in this group had a negative impact on European barracuda and a positive impact on the bottlenose dolphin and small-spotted catshark, due to trophic cascade by predation. Moreover, numerous groups in the model were impacted by groups situated at the base of the food web, such as macroalgae, amphipods and macroplankton. Some groups can have a negative impact on themselves, such as zooplankton and protozoan plankton. Several groups such as opportunistic piscivorous fish, zooplanktivorous fish and decapods had a large impact throughout the entire food web (Fig. 3).

Table 2. Ecological indicators related to the food web structure of the Bonifacio Strait Natural Reserve (BSNR) and Calvi model, statistics, and network flow parameters. The first (BSNR model) displays protection measures, contrary to the second (Calvi) model (Pinnegar \& Polunin 2002). TL: trophic levels

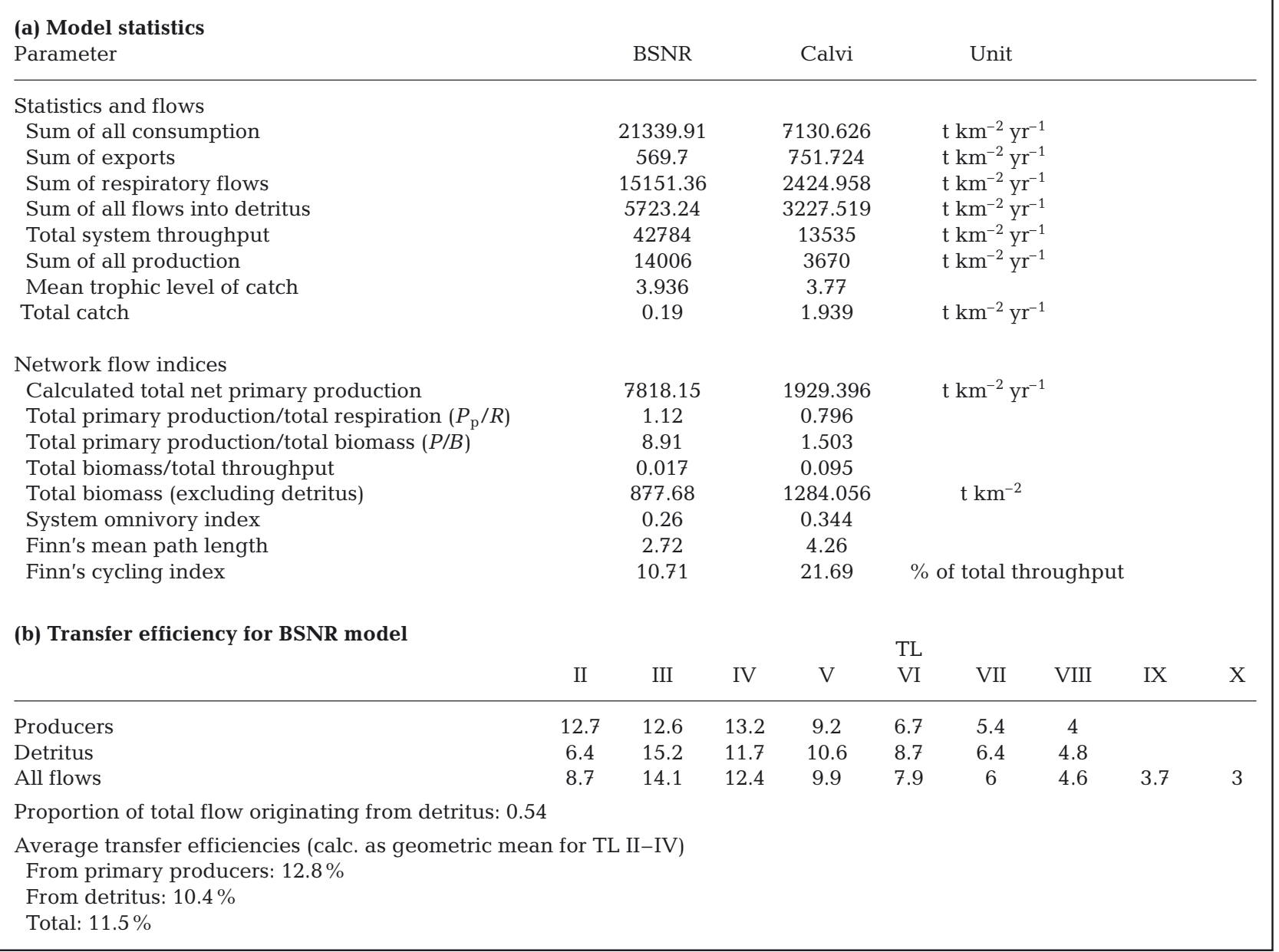




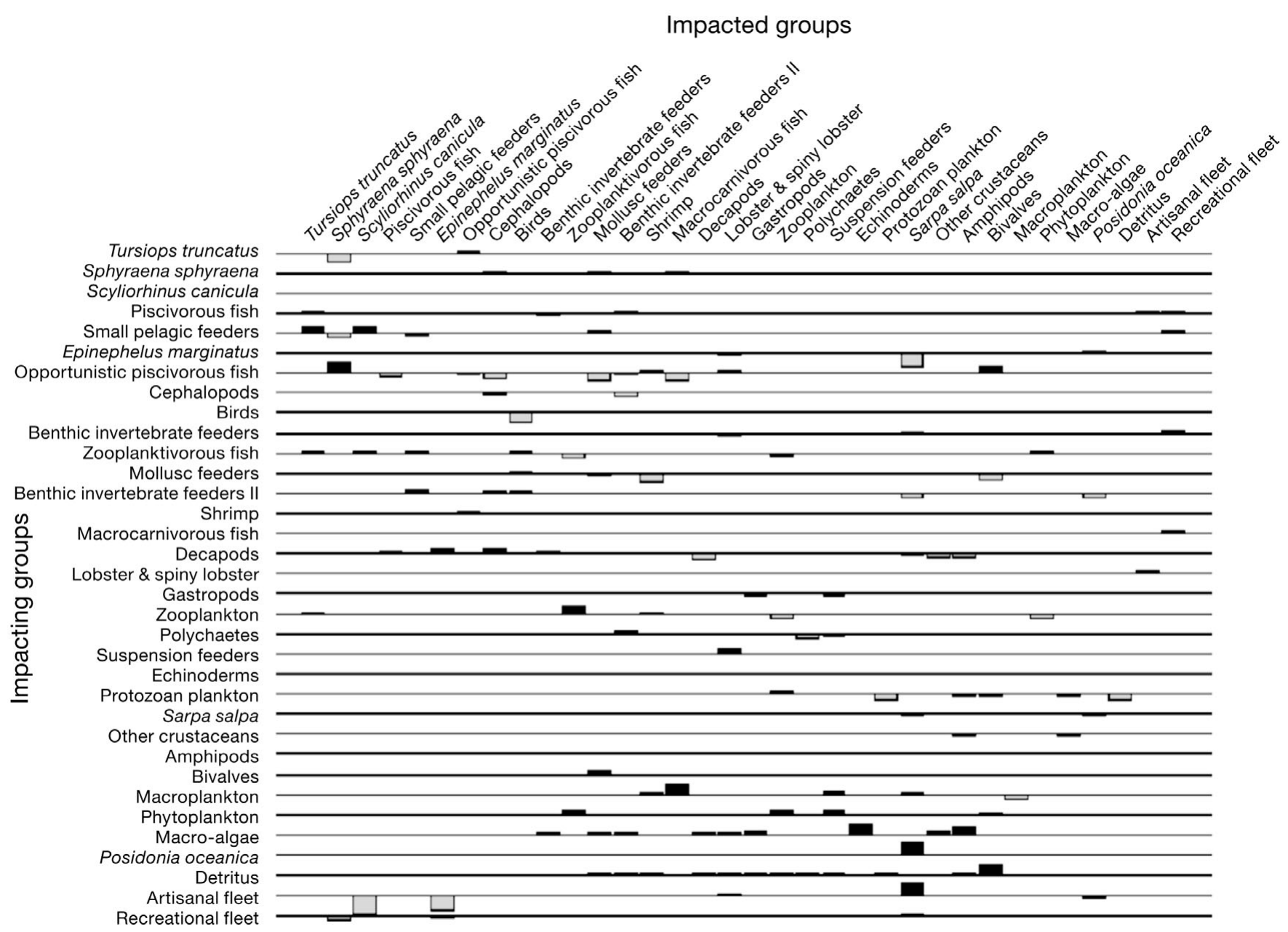

Fig. 3. Mixed trophic impacts analysis from the Bonifacio Strait Natural Reserve (BNSR) model showing the combined direct and indirect trophic impacts that an infinitesimal increase in impacting groups (vertical axis) is predicted to have on impacted groups

(horizontal axis). Black bars: positive impacts (between 0 and 1); grey bars: negative impact (between 0 and -1 )

\section{Ecosim simulations}

Results from simulations using Ecosim showed different response patterns when we simulated variations of both artisanal and recreational fishing efforts (Fig. 4), and we identified 3 categories of response.

Firstly, we focused on groups impacted exclusively by the artisanal fishery, meaning those losing biomass in response to an increase of the artisanal fishery effort. For instance, an increase in this effort induced a decrease in catches for Epinephelus marginatus, benthic invertebrate feeders II and of lobsters/spiny lobsters. For these groups, an increase in recreational fishing effort was without influence. In the case of the lobsters/spiny lobsters group, a total prohibition of the artisanal fishery effort (set to $F=0$ ) would result in an increase in $2.7 \%$ of the system biomass. This amount corresponds to $51 \mathrm{t}$ for the whole area of the BSNR.
Secondly, some groups were impacted by both fisheries, such as piscivorous fish, Sphyraena sphyraena, small pelagic feeders and Scyliorhinus canicula. For these groups there is an additional effect since their biomasses decreased in catches when both fishing efforts rose. For instance, when both fishing efforts were at the maximum in our simulations (4 times the actual level), piscivorous fish and the European barracuda biomasses decreased by 4.7 and $5.4 \%$, respectively. These percentages corresponded to a loss of $131 \mathrm{t}$ for piscivorous fish and of $10 \mathrm{t}$ for $S$. sphyraena.

Thirdly, other groups (zooplanktivorous fish, benthic invertebrate feeders, mollusc feeders and cephalopods) displayed various non-trivial patterns, which were largely due to trophic cascades. For mollusc feeders and cephalopods, an increase in artisanal fishing effort induced an increase in their biomass, but coupled with an increase in recreational fishing effort, this 


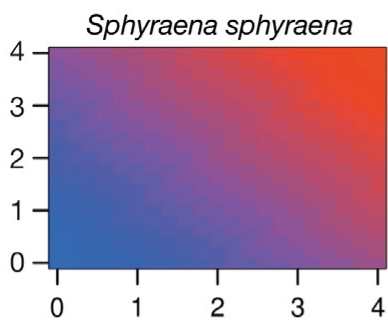

Epinephelus marginatus
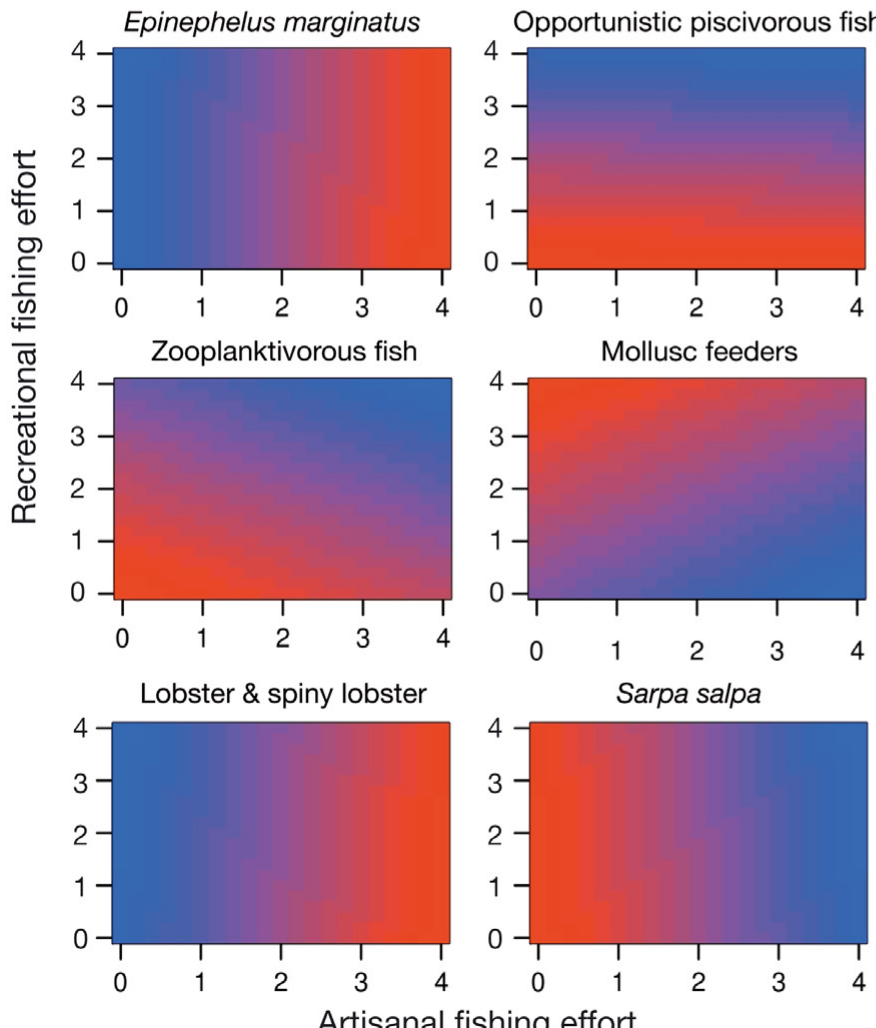

Artisanal fishing effort

biomass eventually decreased. For zooplanktivorous fish and benthic invertebrate feeders, an increase in artisanal fishing effort provoked a decrease in biomass in the system, but, coupled with an increase in recreational fishing effort, this biomass increased.

\section{DISCUSSION}

\section{Ecopath results}

Trophic levels, matter flows and summary statistics

Overall, ecological indicators related to community energetics, community structure, cycling of nutrients, and the comparison with other modelled ecosystems, suggest that the BSNR is a mature ecosystem, similar to most coastal ecosystems. The pedigree index (0.61) representing the model quality is within the range
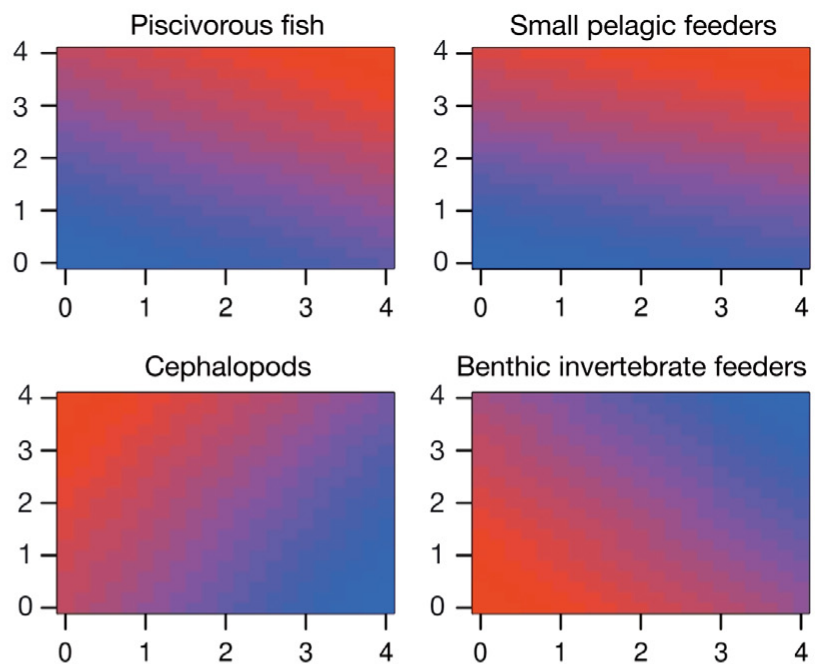

Benthic invertebrate feeders

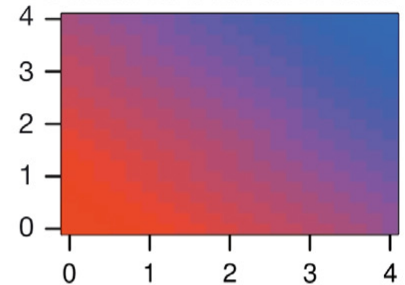

Benthic invertebrate feeders II

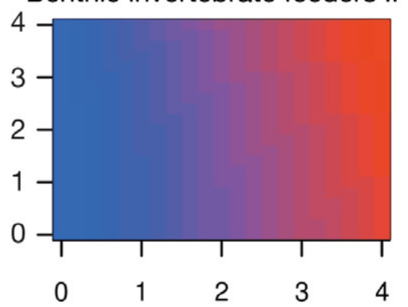

Macrocarnivorous fish

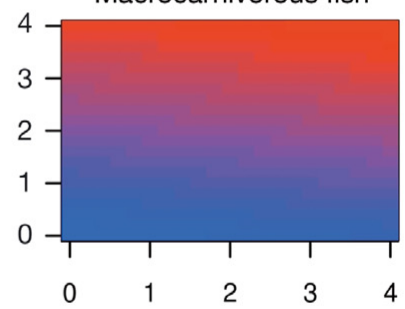

Artisanal fishing effort

Biomass

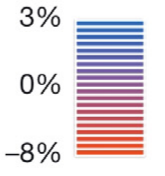

Fig. 4. Combined effects of changes of recreational and artisanal fishing efforts on all fish groups, on one group of cephalopods and on one crustacean group. Red represents a biomass decrease and blue a biomass increase in the ecosystem
( 0.164 to 0.676 ) of the 50 previously constructed models reported in Morissette (2007). TLs of fish species are in accordance with the range of previous results for the Mediterranean (Stergiou \& Karpouzi 2001) as well as with TLs of another Corsican rocky littoral system models with similar attributes (Pinnegar \& Polunin 2004). TLs obtained for bottlenose dolphins (5.22) and for Sphyraena sphyraena (4.96) are higher than TLs recorded by Pauly et al. (1998b) for dolphins (TL = 4.2) and by Ben-Tuvia (1986) for $S$. sphyraena (TL = 4.04). These differences are due to the diet of these 2 groups, which feed on predators, especially on fish species with a TL higher than 3.39, and could be due to MPA effects. Indeed, MPAs are known to promote biomass of large species and top predators (Claudet et al. 2006, Guidetti et al. 2008) increasing, by cascade, the TL of species feeding on them. Conversely, Pauly et al. (1998b) found that the diet of Tursiops truncatus (worldwide) is not exclusively composed of predator 
fishes, but of other items with lower TLs (large squid, small squid, small pelagics and miscellaneous fish) whereas Blanco et al. (2001) found that T. truncatus of the western Mediterranean Sea feeds partly on Phycis sp. and Conger conger. Therefore, it seems realistic that our TL for bottlenose dolphins is higher than that of Pauly et al. (1998b).

Tursiops truncatus is known to use fishing nets as an easily accessible feeding source, damaging or depredating fish caught in the nets (Reeves et al. 2001, Lauriano et al. 2004, Díaz-Lopez 2006). This species attacked, on average, $12.4 \%$ of the nets and, when they attacked, they damaged $8.3 \%$ of individuals caught in nets (Rocklin et al. 2009). Our data show that the fish biomass extracted by dolphins and by the artisanal fishery are similar in the BSNR. Moreover, the bottlenose dolphin and the artisanal fishery target the same groups of species (small pelagic feeders, piscivorous fish, cephalopods, benthic invertebrate feeders) according to Blanco et al. (2001). However, indirect negative interactions between dolphins and fisheries were not demonstrated (Rocklin et al. 2009), and the low level of exploitation (compared to the biomass available in the BSNR) induced by both artisanal fishery and dolphins suggest non-limiting resources and weak competitive interactions.

According to Odum (1969) and Christensen \& Pauly (1993), a low ratio between system primary productivity and biomass $(P / B)$ indicates a developed system, due to high biomasses and low production rates. This ratio ranges from 0 to 200 for 41 Ecopath models. Here the value of $P / B$ (8.91) is low and equivalent to those reported for other coastal areas (Christensen \& Pauly 1993), indicating great abundance of slow-growing individuals.

Odum (1971) explained that the ratio between total primary production and total system respiration $\left(P_{\mathrm{p}} / R\right)$ moves towards unity $\left(P_{\mathrm{p}} / R=1\right)$ for mature systems. For the 41 Ecopath models that were mentioned above, $P_{\mathrm{p}} / R$ values range from 0.8 to 3.2 . Our value of 1.12 is close to 1 , i.e. the lowest boundary of that range, and indicates a very mature system.

The capacity of an ecosystem to entrap and cycle nutrients increases with maturity (Odum 1969) and can be estimated using the Finn's cycling index (Finn 1976). Christensen \& Pauly (1993) found a relation between this index and maturity ranking across the 41 Ecopath models. In the BSNR Ecopath model, the value of Finn's cycling index was $10.71 \%$. This moderate value is in accordance with values found in other coastal areas (Christensen \& Pauly 1993) and once again suggests that our system is mature.

Transfer efficiencies (TE) represent the energy transferred from a trophic level to the next trophic level, through consumption. Since Lindeman (1942), it has often been assumed that TE varies around $10 \%$. Our result $(11.5 \%)$ is in accordance with the range (10 to $15 \%$ ) of values reported in the literature (Christensen \& Pauly 1993). Furthermore, for comparison, TEs are 12.62 and $10 \%$ for the Catalan and Adriatic Sea, respectively (Coll et al. 2006, 2007). To sum up, all these indicators of ecosystem maturity show that the BSNR model is in accordance with other Ecopath coastal models and with theory of trophic flows, suggesting that the model has realistic features despite some uncertainties.

In the mixed trophic impact analysis (Fig. 3) numerous groups at the base of the food web, such as Posidonia oceanica, macroalgae, phytoplankton, macroplankton, and zooplankton, have an impact on higher rank trophic groups by bottom-up predator-prey interactions occurring in the system (Hunter \& Price 1992, Coll et al. 2006). On the other hand, some groups such as zooplanktivorous fishes (Boops boops, Chromis chromis, Atherina sp.) have a strong impact on numerous groups of both higher and lower trophic levels. This zooplanktivorous fish group has a top-down effect on zooplankton and a bottom-up control on predators. These results underline the importance of this key group in the ecosystem and possible wasp-waist predator-prey interactions (Cury et al. 2000, Coll et al. 2006). Opportunistic piscivorous fish species (Pagellus acarne, Apongon imberbis, Scorpaena porcus, etc.) occupy an intermediate trophic position $(\mathrm{TL}=4.2)$ within the fish community and have a large number of trophic interactions with a wide variety of other groups. Changes in their biomass may induce simultaneous positive and negative effects on other groups, which can be interpreted as a wasp-waist effect (Cury et al. 2000).

A weak increase in Epinephelus marginatus leads to a decrease in Sarpa salpa and to an increase in Posidonia oceanica biomass. This food chain was created in accordance with data available in FishBase (Froese \& Pauly 2010), identifying E. marginatus as the unique predator of $S$. salpa and $S$. salpa as the main consumer of $P$. oceanica. The protection of the dusky grouper, an emblematic fish species in the Mediterranean, may have a positive impact on $P$. oceanica meadows by means of a top-down effect. Since $P$. oceanica meadows constitute crucial habitats for nurseries (e.g. Gobert 2002), the management of top predators such as groupers is critical. In the same vein, a recent study showed that protection of large individuals of S. salpa may alter seagrass ecosystems (Prado et al. 2008). This type of investigation is possible in Ecosim through the use of mediation effects (Christensen et al. 2005), but here we only considered food web effects.

Through interaction analyses of the BSNR model, we were able to reproduce complex cascades of trophic 
interactions observed on Mediterranean coasts and in MPAs. One step further than observing cascades, we used such complex interactions to predict the status of the system according to scenarios involving non-trivial combined effects between fishing fleets.

Comparing two neighbour Mediterranean ecosystems: protected vs. non-protected areas

In order to understand the particularity of our system, we carried out a comparison with a non-protected area presenting similar sea surface temperature, habitats and species composition. This comparative analysis was established between 2 Ecopath models on rocky littoral ecosystems (Table 2), one protected (BSNR) and the other in a non-protected neighbour area (Calvi, Corsica; Pinnegar \& Polunin 2004). There are great similarities in the model construction (target fish, invertebrate groups) allowing comparisons of these model outputs. Both ecosystems are mature (with higher values of $P_{\mathrm{p}} / R$ for the BSNR model); the fishing pressure is less and the mean trophic level of catches is higher in the BSNR than in the Calvi ecosystem (for values see Table 2).

The biomass extracted by artisanal fishing in the BSNR $\left(0.09 \mathrm{t} \mathrm{km}^{-2} \mathrm{yr}^{-1}\right)$ is very low compared to that at Calvi's (1.94 t km-2 $\mathrm{yr}^{-1}$ ). The BSNR artisanal fleet is small (40 boats) and the fishing period extends over

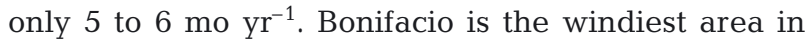
Corsica with $328 \mathrm{~d}$ of wind per year (171 d with wind speed above $58 \mathrm{~km} \mathrm{~h}^{-1}$ ). In the BSNR, a restrictive policy has been enforced on fishing activities since the creation of the MPA (in 1999): the number of professional licenses and the minimum mesh size were controlled and various protected perimeters were delimited. These restrictions tend to decrease the fishing pressure on the protected parts and to increase catches in terms of capture per unit of effort (CPUE) as demonstrated in Mouillot et al. (2008).

Pauly et al. (1998a) established that, with an increasing fishing pressure, the mean TL of catches decreases since fishes with high TLs are primarily targeted (generally benthic and demersal piscivorous). Top predators are thus progressively replaced by fishes with lower TLs, such as invertebrate feeders and planktivorous species. This index (mean TL of catches) is able to reveal the major difference in protection between these 2 ecosystems. The Calvi ecosystem is indeed more exploited than the BSNR, and its mean TL of catches is lower than for the BSNR model (3.77 vs. 3.94, respectively). An alternative explanation of this difference may come from the absence of Epinephelus marginatus $(\mathrm{TL}=4.31$ ) and the small pelagic feeder groups $(\mathrm{TL}=4.54)$ in Calvi catches. Their presence in the
BNSR data could be related to a higher conservation status. E. marginatus was usually targeted by spearfishing and is a relevant indicator species of this activity (Mouillot et al. 2002, Lloret et al. 2008b).

\section{Simulated combined effects of artisanal and recreational fleets}

Within the BSNR, artisanal and recreational fishing activities create a combined pressure on the ecosystem, although this pressure is low compared to the Bay of Calvi. Additional effects were observed when these 2 pressures increased in magnitude. The first level of interpretation was to distinguish which groups were particularly affected by either one or both types of fishing activity. The second level of interpretation was to understand the main trophic links between groups and to predict the combined effects of fishing pressure variations on the food web.

No group of fish represented in Fig. 4 is targeted exclusively by recreational activities. The nature of relations between the 2 types of fisheries is therefore limited to an additional effect or a lack of recreational fishing effect for remarkable groups having a protected status, and for which recreational catches are forbidden (Epinephelus marginatus, lobsters/spiny lobsters).

In the case of Epinephelus marginatus, protected since 1980, recreational fishing has no influence on its stock. However, E. marginatus is occasionally caught by the artisanal fishery. As pointed out above with MTI analysis (Fig. 3), several groups are connected to E. marginatus such as Sarpa alpa, which is itself connected to Posidonia oceanica. So an increase in catches of E. marginatus by artisanal fishing results in an overgrazing of P. oceanica by S. salpa (Fig. 4).

Mollusc feeders such as sparids (Diplodus sargus sargus, D. vulgaris, and D. puntazzo) showed a remarkable pattern (Fig. 4). Indeed, when artisanal fishing effort increases while recreational fishing effort is still limited, the biomass of this group increases. A possible interpretation of this result can be given by observing the position of this group in the network (Fig. 3). The trophic pressure exerted on mollusc feeders by top predators, such as Sphyraena sphyraena and opportunistic piscivorous fish, actually decreases when the fishing effort of the 2 fleets increases. Hence, this latter group of fish may be promoted by overfishing and may provide an erroneous signal of protection efficiency. If all species of Diplodus are present at high biomass, we may conclude that the ecosystem is well protected against fishing pressure, while an intensive artisanal activity may promote the diversity and biomass of such groups while recreational pressure is limited. 
The opposite effect can be observed for zooplanktivorous fish, which are less targeted by both fisheries than other groups, due to policy protection regulations (mesh size authorized: $62.5 \mathrm{~mm}$ in length). A reduction in artisanal and recreational fishing efforts leads to the decrease in this group biomass in the system. When their predators are less exploited, predation on zooplanktivorous fish (forage fish) increases, leading to a decrease in their biomasses.

Based on these results, and the study of Christensen \& Walters (2004), we suggest that recreational and artisanal fleets, by removing predators with high trophic levels, could cause top-down effects and thereby blur the classical patterns which are supposed to emerge when protection is enforced, i.e. an increase in fish biomasses. Hence, going one step further than highlighted by Tetreault \& Ambrose (2007), we suggest that some species groups may provide negative signals (meaning a biomass decrease) when MPAs are set or enforced and such potential patterns are revealed by a trophic modelling approach and mechanistic relationships.

\section{Limitations}

Although this paper deals partly with recreational fisheries, we lack data on recreational catches. As an alternative, we assumed that the percentage of spearfishing represents $40 \%$ of the artisanal production (Lloret et al. 2008b). In addition, we made the assumption that the level of exploitation by boat and shore fishing is common to north-shore Mediterranean countries and we used values proposed by MoralesNin et al. (2005). However, recreational fishing pressure can be very different between sites as a function of human population density, tourist activity, cultural traditions, legislation and management policies. Thus, the chosen production for BSNR recreational fisheries is arbitrary and this choice may influence our results. To overcome this limitation we implemented simulations with a large range of recreational fishing effort $(0$ to $400 \%$ ) including realistic scenarios ranging from a total prohibition of such recreational activities to a strong increase (4-fold the value of artisanal production). The actual production lies between these 2 extremes, but further field investigations are needed to estimate this crucial variable.

Another limitation is the fact that the population dynamics of pelagic species and their home ranges exceed the borders of our area, while our model considers trophic transfer within this area with no external exchanges. This limitation is common to all EwE models which are not designed to include spatial dynamics. One solution would be to increase the model area to capture a larger fraction of their range or to drive their population as an input. However, $85 \%$ of the total number of fish species and $90 \%$ of fish biomass are benthic or demersal with few opportunities to disperse in such rocky Mediterranean habitats (Supplement 1C). The dolphins are also assumed to be sedentary to the BSNR throughout the year (WWF 2007). Thus, we suggest that our results are robust, even if they do not include migrations of pelagic species, since the main biomasses belong to sedentary species.

Our model cannot take spillover into account, an essential process by which MPAs sustain fishing activity in their neighboring areas (Pérez-Ruzafa et al. 2008, Forcada et al. 2009). However, all fishing activities tend to concentrate in the vicinity of no-take areas, which may lessen the spillover effect at a regional scale (Goni et al. 2008, Stelzenmüller et al. 2008). The amount of biomass exported from no-take areas towards exploited areas within and around the BSNR is of great interest to assess fully the benefit of protection. Using appropriate spatial data, an Ecospace approach would be useful to assess the function of such complex multiple-use and partial MPAs.

\section{CONCLUSIONS}

Overall, our results illustrate the utility of systemic approaches and the value of modelling tools in managing MPAs and predicting the ecosystem level consequences of socio-political conservation decisions. The BSNR model is a preliminary assessment of the combined effect of different types of fleets on a protected area, which takes into account the overall trophic links from the bottom to the top of the food web. After comparison with another Mediterranean coastal model, it appears that protection measures may have an impact on the mean trophic level of catches. Managers of the BNSR predict an increase in recreational fishing activities while the fishing effort from the artisanal fishery may stabilize. Considering the effect of recreational fishing on coastal ecosystems, and the predictions made by managers, it seems important to create new regulation policies for recreational activities.

This would necessitate the delimitation of more areas restricted to recreational activities but open to threatened artisanal fisheries. The effects of fishery interactions on food webs would then deserve to be studied using a spatial approach that takes into account dispersal rate, preferred habitats of species and variation in the size of protected areas (Pérez-Ruzafa et al. 2008). The BSNR Ecopath model can also be used to interpret how other threats, such as global change, species invasion and habitat destruction, can affect the trophic web and the sustainability of coastal fisheries. 
Acknowledgements. We thank the staff of the Bonifacio Strait Natural Reserve for collecting the data. The study was partially funded by the PAMPA project through the LITEAU III program (French Ministry of Ecology and Sustainable Development). The authors are grateful to Pierre Lopez for drawing the map of the Bonifacio Straits Natural Reserve. Our research also benefited from 2 ANR projects (AMPHORE, GAIUS) which examined the effect of marine protected areas. We also thank the 4 anonymous referees for helpful comments on the manuscript.

\section{LITERATURE CITED}

Bauchot M, Pras A (1980) Guide des poissons marins d'Europe. Delachaux et Niestlé, Lausanne

Ben-Tuvia A (1986) SphyraenidaeIn: Whitehead PJP, Bauchot ML, Hureau JC, Nielsen J, Tortonese E (eds) Fishes of the north-eastern Atlantic and the Mediterranean, Vol. 3. UNESCO, Paris, p 1194-1196

Beverton RJH, Holt SJ (1956) A review of methods for estimating mortality rates in fish populations, with special references to sources of bias in catch sampling. Rapp PV Réun Cons Int Explor Mer 140:67-83

Blanco C, Salomon O, Raga J (2001) Diet of the bottlenose dolphin (Tursiops truncatus) in the western Mediterranean Sea. J Mar Biol Assoc UK 81:1053-1058

Bohnsack JA, Bannerot SP (1986) A stationary visual census technique for quantitatively assessing community structure of coral reef fishes. NOAA Tech Rep NMFS 41:1-15

Bosc E, Bricaud A, Antoine D (2004) Seasonal and interannual variability in algal biomass and primary production in the Mediterranean Sea, as derived from 4 years of SeaWiFS observations. Global Biogeochem Cycles 18:GB1005, doi: 10.1029/2003GB002034.

Christensen V, Pauly D (1993) Flow characteristics of aquatic ecosystems. In: Christensen V, Pauly D (eds) Trophic models of aquatic ecosystems. ICLARM, Manila, p 338-352

> Christensen V, Walters CJ (2004) Ecopath with Ecosim: methods, capabilities and limitations. Ecol Model 172:109-139

Christensen V, Walters CJ, Pauly D (2005) Ecopath with Ecosim: a user's guide. Fisheries Center, University of Bristish Columbia, Vancouver

Claudet J, Pelletier D, Jouvenel JY, Bachet F, Galzin R (2006) Assessing the effects of marine protected area (MPA) on a reef fish assemblage in a northwestern Mediterranean marine reserve: identifying community-based indicators. Biol Conserv 130:349-369

Coleman FC, Figueira WF, Ueland JS, Crowder LB (2004) The impact of United States recreational fisheries on marine fish populations. Science 305:1958-1960

Coll M, Palomera I, Tudela S, Sarda F (2006) Trophic flows, ecosystem structure and fishing impacts in the South Catalan Sea, northwestern Mediterranean. J Mar Syst 59: 63-96

Coll M, Santojanni A, Palomera I, Tudela S, Arneri E (2007) An ecological model of the northern and central Adriatic Sea: analysis of ecosystem structure and fishing impacts. J Mar Syst 67:119-154

Cooke SJ, Cowx IG (2004) The role of recreational fishing in global fish crises. Bioscience 54:857-859

> Cury P, Bakun A, Crawford R, Jarre A, Quinones R, Shannon L, Verheye H (2000) Small pelagics in upwelling systems: patterns of interaction and structural changes in 'waspwaist' ecosystems. ICES J Mar Sci 57:603-618

> Cury P, Shannon LJ, Roux JP, Daskalov GM, Jarre A, Moloney CL, Pauly D (2005) Trophodynamic indicators for an ecosystem approach to fisheries. ICES J Mar Sci 62: 430-442

Cury PM, Shin YJ, Planque B, Durant JM and others (2008) Ecosystem oceanography for global change in fisheries. Trends Ecol Evol 23:338-346

> Díaz-López B (2006) Interactions between Mediterranean bottlenose dolphins (Tursiops truncatus) and gillnets off Sardinia, Italy. ICES J Mar Sci 63:946-951

Dolnicar S, Grabler K, Mazanec JA (1999) A tale of three cities: perceptual charting for analyzing destination images in: consumer psychology of tourism, hospitality and leisure. CAB International, New York, NY

> Dulvy NK, Polunin NVC (2004) Using informal knowledge to infer human-induced rarity of a conspicuous reef fish. Anim Conserv 7:365-374

Finn JT (1976) Measures of ecosystem structure and function derived from analysis of flows. J Theor Biol 56:363-380

> Forcada A, Valle C, Bonhomme P, Criquet G, Cadiou G, Lenfant P, Sanchez-Lizaso J (2009) Effects of habitat on spillover from marine protected areas to artisanal fisheries. Mar Ecol Prog Ser 379:197-211

Froese R, Pauly D (2010) FishBase. World Wide Web electronic publication. www.fishbase.org, version (01/2010)

> Gardmark A, Jonzen N, Mangel M (2006) Density-dependent body growth reduces the potential of marine reserves to enhance yields. J Appl Ecol 43:61-69

> Gascuel D (2005) The trophic-level based model: a theoretical approach of fishing effects on marine ecosystems. Ecol Model 189:315-332

Gobert S (2002). Variations spatiale et temporelle de l'herbier à Posidonia oceanica (L.) Delile (Baie de la RevellataCalvi-Corse). PhD thesis, Université de Liége, Liége

Gómez S, Lloret J, Demestre M, Riera V (2006) The decline of the artisanal fisheries in Mediterranean coastal areas: the case of Cap de Creus. Coast Manag 34:217-232

Goni R, Adlerstein S, Alvarez-Berastegui D, Forcada A and others (2008) Spillover from six western Mediterranean marine protected areas: evidence from artisanal fisheries. Mar Ecol Prog Ser 366:159-174

Guidetti P, Terlizzi A, Fraschetti S, Boero F (2003) Changes in Mediterranean rocky-reef fish assemblages exposed to sewage pollution. Mar Ecol Prog Ser 253:269-278

> Guidetti P, Milazzo M, Bussotti S, Molinari A and others (2008) Italian marine reserve effectiveness: Does enforcement matter? Biol Conserv 141:699-709

Halpern BS, Walbridge S, Selkoe KA, Kappel CV and others (2008) A global map of human impact on marine ecosystems. Science 319:948-952

Harmelin-Vivien M, Le Direach L, Bayle-Sempere J, Charbonnel E and others (2008) Gradients of abundance and biomass across reserve boundaries in six Mediterranean marine protected areas: evidence of fish spillover? Biol Conserv 141:1829-1839

Hunter MD, Price PW (1992) Playing chutes and ladders heterogeneity and the relative roles of bottom-up and topdown forces in natural communities. Ecology 73:724-732

- Jackson JBC, Kirby MX, Berger WH, Bjorndal KA and others (2001) Historical overfishing and the recent collapse of coastal ecosystems. Science 293:629-638

Jamet JL, Jean N, Boge G, Richard S, Jamet D (2005) Plankton succession and assemblage structure in two neigbouring littoral ecosystems in the north-west Mediterranean Sea. Mar Freshw Res 56:69-83

> Kavanagh P, Newlands N, Christensen V, Pauly D (2004) Automated parameter optimization for Ecopath ecosystem models. Ecol Model 172:141-149

Lauriano G, Fortuna CM, Moltedo G, Notarbartolo di Sciara G 
(2004) Interactions between common bottlenose dolphins (Tursiops truncatus) and the artisanal fishery in Asinara Island National Park (Sardinia): assessment of catch damage and economic loss. J Cetacean Res Manag 6:165-173

Legendre P, Legendre L (1998) Numerical ecology. Elsevier Science BV, Amsterdam

Lindeman R (1942) The trophic-dynamic aspect of ecology. Ecology 23:399-418

Lloret J, Zaragoza N, Caballero D, Riera V (2008a) Biological and socioeconomic implications of recreational boat fishing for the management of fishery resources in the marine reserve of Cap de Creus (NW Mediterranean). Fish Res 91:252-259

Lloret J, Zaragoza N, Caballero D, Font T, Casadevall M, Riera V (2008b) Spearfishing pressure on fish communities in rocky coastal habitats in a Mediterranean marine protected area. Fish Res 94:84-91

Lotze HK, Lenihan HS, Bourque BJ, Bradbury RH and others (2006) Depletion, degradation, and recovery potential of estuaries and coastal seas. Science 312:1806-1809

Lubchenco J, Palumbi SR, Gaines SD, Andelman S (2003) Plugging a hole in the ocean: the emerging science of marine reserves. Ecol Appl 13:3-7

Meyer CG (2007) The impacts of spear and other recreational fishers on a small permanent marine protected area and adjacent pulse fished area. Fish Res 84:301-307

Miniconi R (1994) Les poissons et la pêche en Méditerranée: La Corse. Alain Piazzola \& La Marge, Ajaccio

Morales-Nin B, Moranta J, Garcia C, Tugores MP, Grau AM, Riera F, Cerda M (2005) The recreational fishery off Majorca Island (western Mediterranean): some implications for coastal resource management. ICES J Mar Sci 62: $727-739$

Morissette L (2007) Complexity, cost and quality of ecosystem models and their impact on resiliance: a comparative analysis, with emphasis on marine mammals and the gulf of St. Lawrence. PhD thesis, University of British Columbia, Vancouver

Mouillot D, Culioli JM, Chi TD (2002) Indicator species analysis as a test of non-random distribution of species in the context of marine protected areas. Environ Conserv 29: 385-390

Mouillot D, Culioli J, Pelletier D, Tomasini J (2008) Do we protect biological originality in protected areas? A new index and an application to the Bonifacio Strait Natural Reserve. Biol Conserv 141:1569-1580

Odum EP (1969) Strategy of ecosystem development. Science 164:262-270

Odum EP (1971) Fundamentals of ecology. Saunders, Philadelphia, PA

Pauly D (1984) Fish population dynamics in tropical waters: a manual for use with programmable calculators. ICLARM, Manila

Pauly D (1989) Food-consumption by tropical and temperate fish populations - some generalizations. J Fish Biol 35: 11-20

Pauly D, Christensen V, Dalsgaard J, Froese R, Torres F (1998a) Fishing down marine food webs. Science 279: 860-863

Editorial responsibility: Konstantinos Stergiou, Thessaloniki, Greece
Pauly D, Trites AW, Capuli E, Christensen V (1998b) Diet composition and trophic levels of marine mammals. ICES J Mar Sci 55:467-481

> Pauly D, Christensen V, Walters C (2000) Ecopath, Ecosim, and Ecospace as tools for evaluating ecosystem impact of fisheries. ICES J Mar Sci 57:697-706

> Pérez-Ruzafa A, Marcos C, García-Charton JA, Salas F (2008) European marine protected areas (MPAs) as tools for fisheries management and conservation. J Nat Conserv 16: $187-192$

> Pinnegar JK, Polunin NVC (2004) Predicting indirect effects of fishing in Mediterranean rocky littoral communities using a dynamic simulation model. Ecol Model 172:249-267

Pluquet F (2006) Evolution récente et sédimentation des plates-formes continentales de la Corse. PhD thesis, Université de Corse, Pascal Paoli, Corte

Prado P, Farina S, Tomas F, Romero J, Alcoverro T (2008) Marine protection and meadow size alter fish herbivory in seagrass ecosystems. Mar Ecol Prog Ser 371:11-21

Reeves RR, Read AJ, Notarbartolo di Sciara G (2001) Report of the workshop on interactions between dolphins and fisheries in the Mediterranean: evaluation of mitigation alternatives. Report of ICRAM, Rome

Rocklin D, Santoni M, Culioli J, Tomasini J, Pelletier D, Mouillot D (2009) Changes in the catch composition of artisanal fisheries attributable to dolphin depredation in a Mediterranean marine reserve. ICES J Mar Sci 66:699-707

Russ GR, Alcala AC (1996) Marine reserves: rates and patterns of recovery and decline of large predatory fish. Ecol Appl 6:947-961

Samoilys M, Carlos G (2000) Determining methods of underwater visual census for estimating the abundance of coral reef fishes. Environ Biol Fishes 57:289-304

Stelzenmüller V, Maynou F, Bernard G, Cadiou G and others (2008) Spatial assessment of fishing effort around European marine reserves: implications for a successful fisheries management. Mar Pollut Bull 56:2018-2026

> Stergiou KI, Karpouzi VS (2001) Feeding habits and trophic levels of Mediterranean fish. Rev Fish Biol Fish 11: $217-254$

> Stobart B, Warwick R, Gonzalez C, Mallol S, Diaz D, Renones O, Goni R (2009) Long-term and spillover effects of a marine protected area on an exploited fish community. Mar Ecol Prog Ser 384:47-60

> Tetreault I, Ambrose RF (2007) Temperate marine reserves enhance targeted but not untargeted fishes in multiple no take MPAs. Ecol Appl 17:2251-2267

Ulanowicz R, Puccia C (1990) Mixed trophic impacts in ecosystems. Coenoses 5:7-16

> Walters C, Christensen V, Pauly D (1997) Structuring dynamic models of exploited ecosystems from trophic mass-balance assessments. Rev Fish Biol Fish 7:139-172

Worm B, Barbier E, Beaumont N, Duffy J and others (2006) Impacts of biodiversity loss on ocean ecosystem services. Science 314:787-790

WWF (World Wide Fund for Nature) (2007) Summary of Life Linda 2003-2007: limiting negative interactions between dolphins and human activities. WWF; www.lifelinda.org/ upload/tele/vulgarisationang_ce.pdf

Submitted: October 20, 2009; Accepted: May 27, 2010 Proofs received from author(s): August 11, 2010 